\title{
ITAAM Framework: An Adaptive Approach to Design, Measure and Improve IT Agility
}

\author{
Yassine Rdiouat \\ Hassan 1st University, Settat city, Morocco \\ E-mail: yassine.rdiouat@gmail.com \\ Wafaa Dachry and Alami Semma \\ Hassan 1st University, Settat city, Morocco \\ E-mail: wafaa.dachry@gmail.com, a.semma@uhp.ac.ma
}

Received: 14 May 2017; Accepted: 27 July 2017; Published: 08 October 2017

\begin{abstract}
In order to respond effectively to rapid and unpredictable changes in the business environment, information systems are forced to adapt by developing agility skills, so the company can grow or even survive in this changing environment. Thus, it is necessary to provide organizations an approach indicating how to design, measure and improve the agility of their information systems. In this context an iterative, integrated, flexible and balanced framework has been developed. This framework, called ITAAM (Information Technology Agility Assessment Model), is founded upon a simple model, derived from the Balanced ScoreCard methodology that is widely used as a system of performance measurement. Basically, the structure of our approach is composed of a conceptual framework, an evaluation methodology, an agility grid and a scoring system for the Global Agility Index calculation. Moreover, within every assessment cycle, the agility level is identified and a set of recommendations are provided as well as the necessary adjustment guidelines concerning the whole organization. As a result, sustainability and continuous improvement of agility can be ensured, which represents the main goal of our new construct.
\end{abstract}

Index Terms-ITAAM, Agility, Agile Information System, IT Agility, IS Agility, Agile Enterprise, Agile Organization, Agile BSC, Balanced Scorecard.

\section{INTRODUCTION}

The concept of agility is applied to several research fields, like Agile project management [2][6] or Agile Information Systems Development [3][4][10][13]. Other area are explored, such as, IT infrastructure [16], IS development [17], IS organization, and IS personnel as described by Salmela et al [9] in a recent literature review. However, research has shown that neither a widely accepted definition nor commonly used frameworks or concepts exist. In this context, enterprise information systems are regarded as enablers for business agility achievement [14][15].

In their previous study, Rdiouat et al. [7] have introduced a framework to define and conceptualize the concept of agility applied to IT organizations. They developed a new Balanced ScoreCard of IT agility called IS Agility BSC or Agile BSC through four perspectives: Business Contribution, User Orientation, and Operational Excellence in addition to Innovation and Competitiveness perspective.

The purpose of this paper is to design an integrated approach called ITAAM (Information Technology Agility Assessment Model). Several contributions have been introduced which can be summarized as follows:

- Adaptation of the conceptual model presented in our previous work [7] that allows designing IT agility through four perspectives.

- A methodology of IT agility assessment and consequently its continuous improvement.

- An evaluation system based on an agility grid, called ITAAM grid. This grid contains a set of questions for each perspective and a scoring system defining calculation rules of IT agility level.

- A maturity model to identify the real need of IT agility in order to improve it permanently.

- An Agile Eval tool is developed to industrialize the evaluation process.

\section{ITAAM FRAMEWORK}

ITAAM is a pragmatic approach translating, in action, the organization's strategy concerning the agility of its IT. It is developed with the perspective to provide managers with a framework, indicating how to pragmatically manage and improve the agility of their IT organizations.

The ITAAM approach is a balanced approach. Indeed, it provides a balanced scorecard based-model to measure the performance of IT agility through four perspectives: Business Contribution, User Orientation, Operational Excellence in addition to innovation and competitiveness perspective. Each perspective is further structured into three levels: mission, key success factors, and evaluation criteria. 
Moreover, the ITAAM approach is essentially agile thanks to its evaluation system, since it has the ability to continuously adjust to the organization requirements. Also, this system evaluates and calculates the actual agility by detecting the non-coverage gaps, as well as the necessary adjustment guidelines. This system relies primarily on agility grid that is composed of four questionnaires. Through these questionnaires, our approach allows to collect the information needed to assess the agility of each perspective. In this regard, a computer tool is developed to automate the evaluation process. Indeed, it allows storing and analyzing the collected items in order to determine the IT agility level.

ITAAM is also iterative to achieve progressively and continuously the target IT agility level. This approach defines agility as the ability of information system to (1) constantly innovate and maintain the company's competitive conditions in a changing environment (2) mobilize processes and agile internal structures to take advantage of future opportunities (3) satisfy and maintain an agile relationship with users (4) generate business value of IT with a faster Time-to-Market [7]. The Fig.1 illustrates the main components of ITAAM:

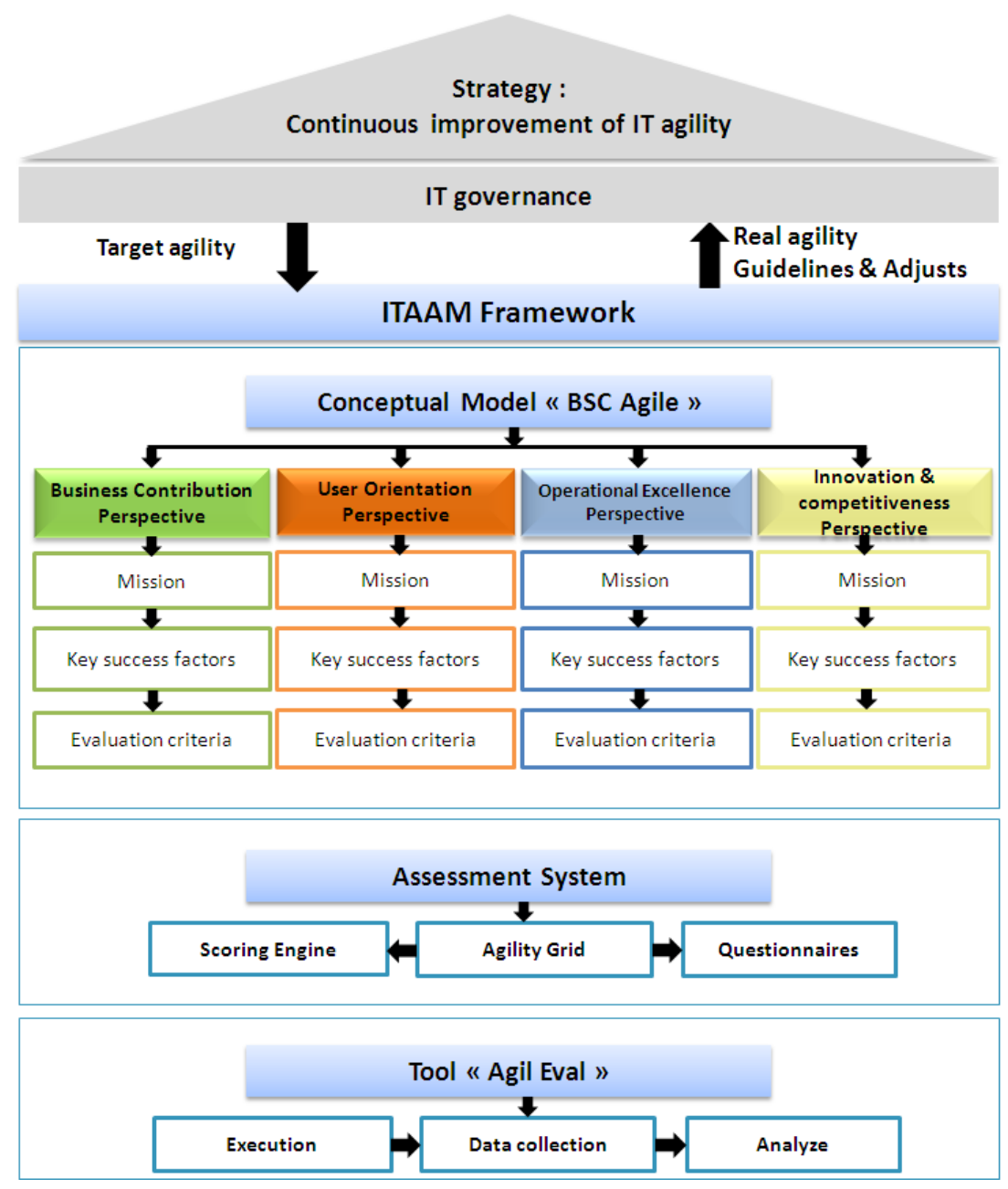

Fig.1. ITAAM Framework's Architecture

\section{PeRsPeCtives OF -BSC AgILE- COMPONENT}

The Fig.2 describes the perspectives of BSC Agile component and their cause-to-effect relationships. The perspectives of this component are initially identified from the BSC approach. These perspectives are then reviewed and adapted to the field of information systems agility as defined in our previous work [7].

Basically, BSC Agile is structured into four perspectives characterized by an explicit causal relationship. Each perspective is containing a mission and a set of key success factors that are not entirely independent, since there may have mutual influences between them. For example, a good performance of the key success factor Human resources agility from the Innovation and Competitiveness perspective generally leads to improvement in the key success factor Structures agility from the Operational Excellence perspective, which should improve the degree of Partnership with users in the User Orientation perspective, and could ultimately lead to the improvement of Business/IT alignment from the Business Contribution perspective. Each of these key success factors has criteria that are evaluated through metrics. 


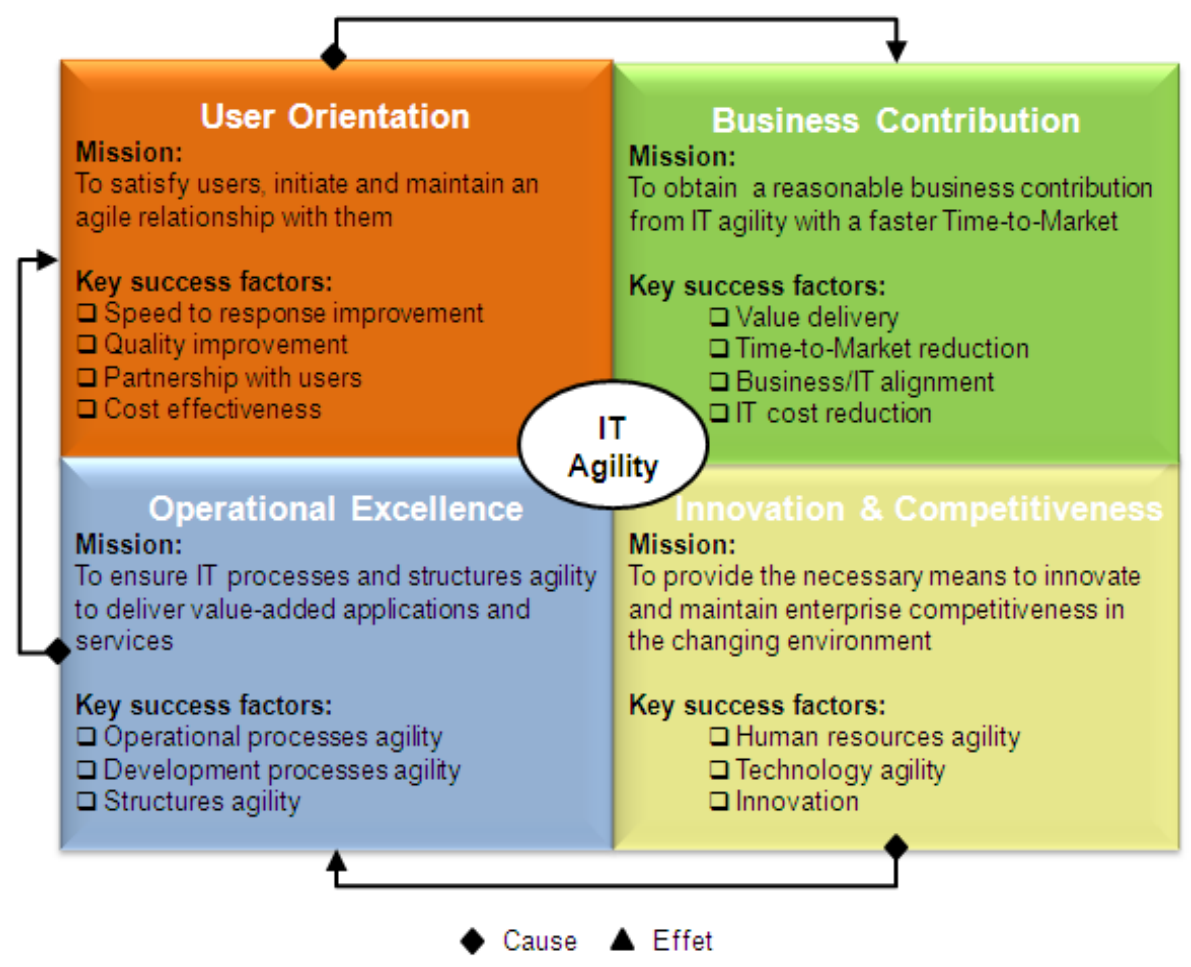

Fig.2. Perspectives of the -BSC Agile- component and their cause-and-effect relationships [7]

\section{A. Business Contribution perspective}

As shown in Fig.3, the ITAAM BSC is closely linked to the business objectives of the enterprise through the business contribution perspective (Value delivery, Timeto-Market reduction, Business/IT alignment and IT cost reduction) [7].

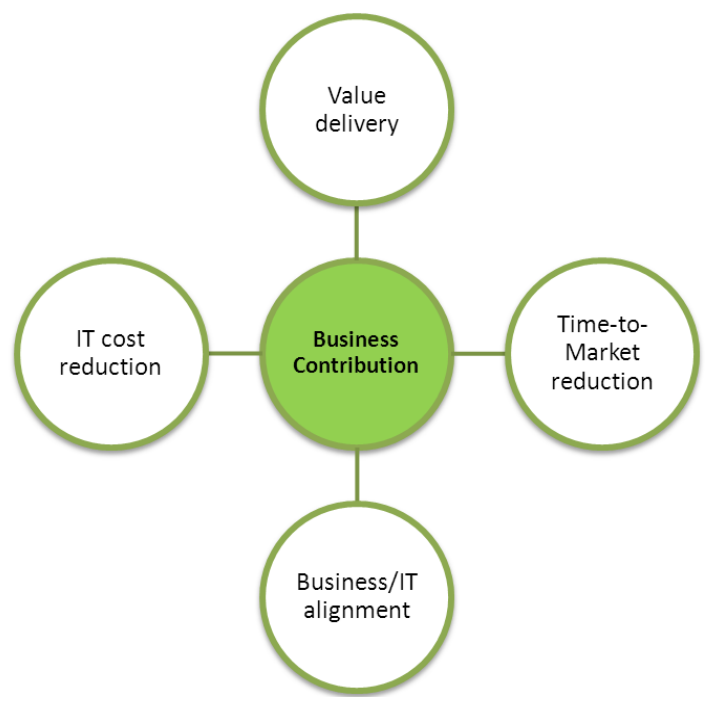

Fig.3. Business contribution perspective

\section{B. User orientation perspective}

This perspective provides answers to key stakeholder's questions about IT agility to ensure operational efficiency (time, quality and cost), customer satisfaction, initiating and maintaining an agile partnership with its users. The Fig.4 shows key success factors of this perspective that are adapted from [7] as described below:

- Speed to response improvement

- Quality improvement

- Partnership with users

- Cost effectiveness

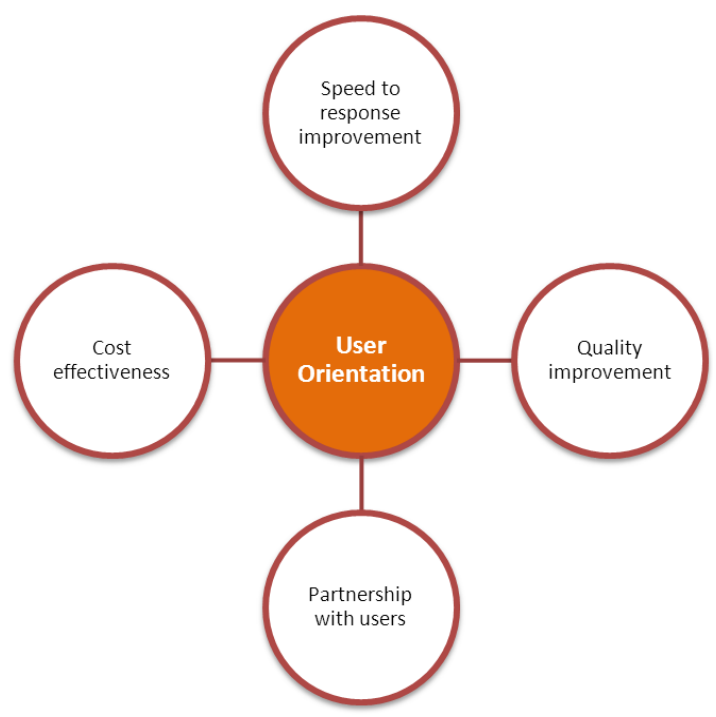

Fig.4. User orientation perspective

\section{Operational excellence perspective}

The mission of this perspective is to ensure the operational agility of processes and structures of the IT organization [7]. The goal is to develop and deliver value-added applications and services for both users and the enterprise. Indeed, IT organization must inevitably 
increase the personalization and development of new products and services and ensure a greater variety of these in response to changes. The Fig.5 shows the main key success factors identified for this perspective:

- Operational processes agility

- Development processes agility

- $\quad$ Structures agility

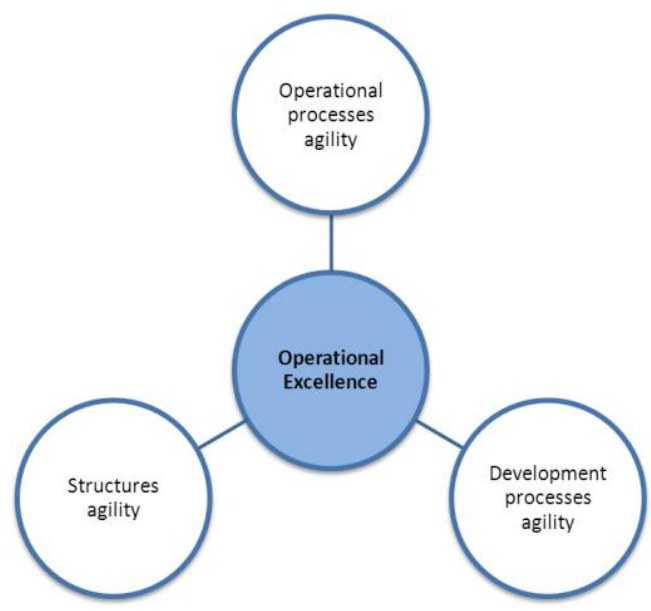

Fig.5. Operational excellence perspective

\section{Innovation and competitiveness}

This perspective evaluates the agility from the point of view of the IT organization itself. It is based on key success factors, as described in Fig.6, basically:
- Human resources agility

- Technology agility

- Innovation

These three components are also the main drivers of agility as described by Sharifi et Zhang [18].

Regarding Sharifi et al [19], innovation is the successful exploration of new ideas about products, services and procedures enabling the information system to be a source of innovation for the company. As a result, the innovation porters position the IT as a key driver in enterprise innovation [20]. However, technological innovation on purely IT aspects cannot be an aim in itself if it is unable to generate business value for the company.

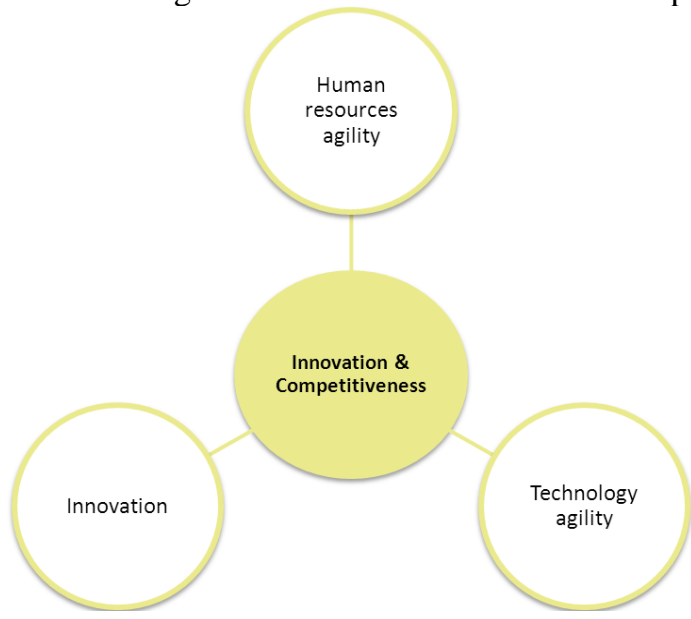

Fig.6. Innovation and competitiveness perspective

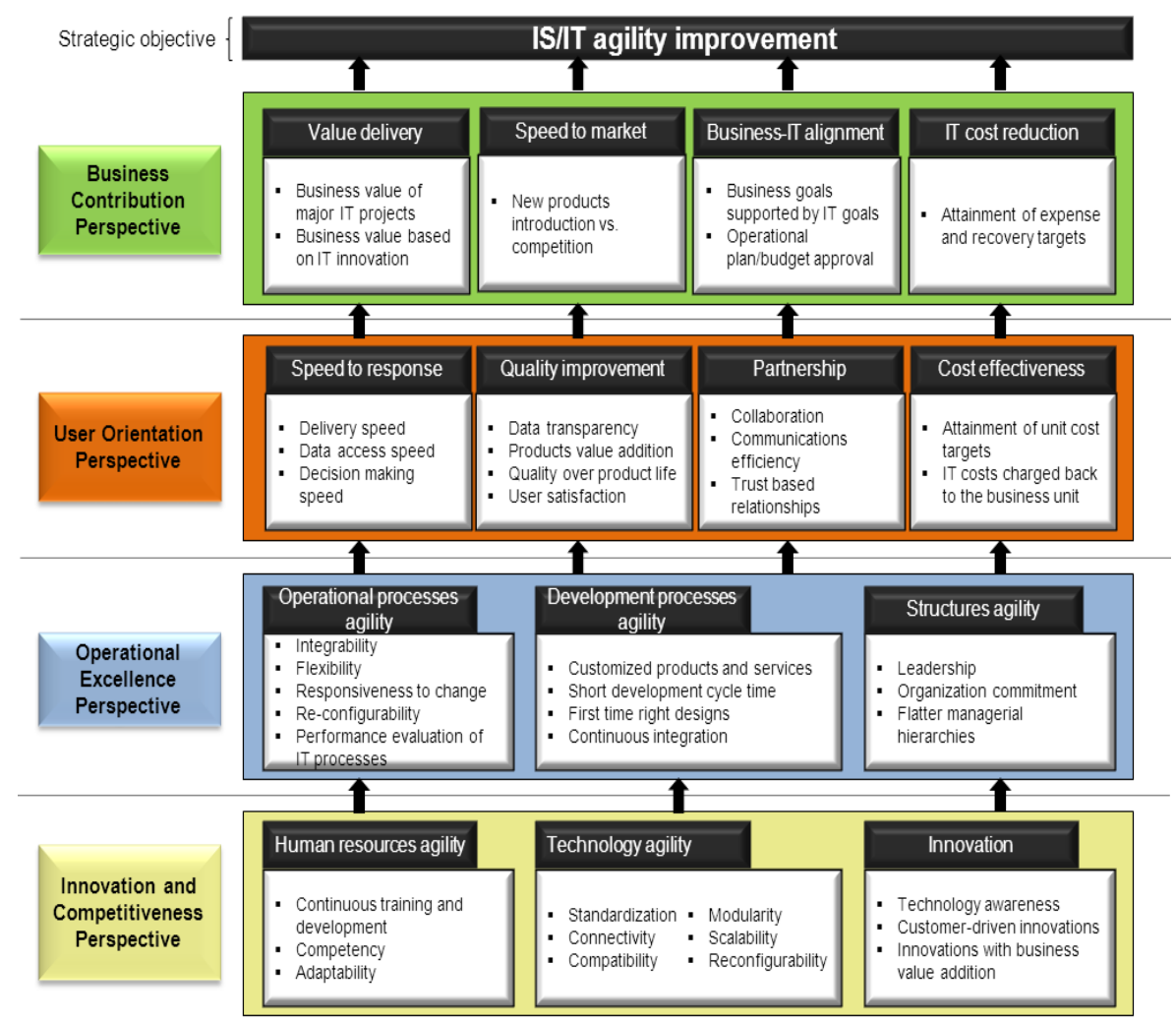

Fig.7. Strategic map of the -BSC Agile- component adapted from Rdiouat et al. [7] 


\section{STRATEGIC MAP}

The Fig.7 shows the strategic map of BSC Agile component, it presents the cause-and-effects relationships between perspectives. An example of these cause-andeffect relationships is that the organization aims to improve sustainably the Time-to-Market. In order to achieve this goal, the level of partnership and synergy between the business team and IT team must increase, and all business requests must be processed in a timely manner (user orientation perspective). This means that the agility of business and development processes must be improved in order to respond quickly to changes, and that internal structures must promote more leadership to accelerate the decision-making process, as well as, the IT organization is sufficiently agile for a better collaboration with both business team and IT team. The objectives of operational excellence can only be achieved if the information system continuously improves its capacity for innovation and technological progress and if the sense of agility among collaborators is perfected by learning, competency and adaptability (innovation and competitiveness perspective).

\section{AGILITY GRID}

The agility grid allows analyzing and auditing IT agility. It is founded on four questionnaires that combine, for each ITAAM perspective, a set of questions per key success factor and evaluation criterion.

The questions are essentially considered as indicators used by the evaluator to measure special aspects of IT agility from different perspectives in order to determine its current and aimed agility level. These questions can be evaluated through lekert-5 metrics. In this context, a computer tool is developed to collect answers and execute business rules to automatically determine the agility level of the IT as well as the appropriate recommendations and guidelines.

The next challenge is to build a reference grid, which allows generating the appropriate questionnaires for each case studied according to the ITAAM methodology. The examples of questions formulated in this paper are the result of bibliographic research, including the definition of ITAAM criteria and their areas of application. During this exercise, some key success factors and criteria are further decomposed or categorized in order to better meet and structure their associated issues. As an example from the innovation and competitiveness questionnaire, in the TOGAF Framework [11], technology is defined as the composition of applications, software and hardware infrastructure, and data. Based on this definition, the questions of the Agility of technology factor are elaborated. Indeed, to measure the performance of a criterion, in this case Standardization, it is necessary to formulate questions to measure the standardization of each of technology components. Similarly, the criterion Innovation with business added value brings together six types of innovation as described by [1] namely, commercial innovation, organizational innovation, technological innovation, product innovation, process innovation and business model innovation. It makes sense to formulate questions to measure the performance of this criterion for each of the above categories.

Below is an extract from the questionnaire prepared for the Innovation and Competitiveness perspective.

Table 1. Excerpt from the ITAAM questionnaire of the innovation and competitiveness perspective

\begin{tabular}{|c|c|c|c|}
\hline $\begin{array}{c}\text { Key } \\
\text { success } \\
\text { factor }\end{array}$ & $\begin{array}{l}\text { Evaluation } \\
\text { Criteria }\end{array}$ & & Question \\
\hline \multirow{3}{*}{$\begin{array}{l}\text { IC1- } \\
\text { Human } \\
\text { resources } \\
\text { agility }\end{array}$} & $\begin{array}{c}\text { IC11- } \\
\text { Continuous } \\
\text { training and } \\
\text { development }\end{array}$ & IC11.a & $\begin{array}{c}\text { Dose the training plan } \\
\text { cover the real needs of } \\
\text { employees? }\end{array}$ \\
\hline & $\begin{array}{l}\text { IC12- Versatility } \\
\text { and competency }\end{array}$ & IC12.a & $\begin{array}{l}\text { On what scale can you } \\
\text { qualify the versatility } \\
\text { level of employees? }\end{array}$ \\
\hline & $\begin{array}{c}\text { IC13- } \\
\text { Adaptability }\end{array}$ & IC13.a & $\begin{array}{c}\text { Do the employees } \\
\text { accept changes } \\
\text { positively? }\end{array}$ \\
\hline \multirow{4}{*}{$\begin{array}{c}\text { IC2- } \\
\text { Technolog } \\
\text { y agility }\end{array}$} & $\begin{array}{c}\text { IC21- } \\
\text { Standardisation }\end{array}$ & IC21.a & $\begin{array}{c}\text { Does the enterprise use } \\
\text { standards for its } \\
\text { hardware } \\
\text { infrastructure? }\end{array}$ \\
\hline & $\begin{array}{c}\text { IC23- } \\
\text { Compatibility }\end{array}$ & IC23.a & $\begin{array}{c}\text { What is the } \\
\text { compatibility level of } \\
\text { IT infrastructure? }\end{array}$ \\
\hline & IC24-Modularity & IC24.a & $\begin{array}{c}\text { What is the decoupling } \\
\text { degree of IT } \\
\text { components? }\end{array}$ \\
\hline & IC25-Scalability & IC25.a & $\begin{array}{c}\text { What is the scalability } \\
\text { level of hardware } \\
\text { infrastructure? }\end{array}$ \\
\hline \multirow{3}{*}{$\begin{array}{c}\text { IC3- } \\
\text { Innovation }\end{array}$} & $\begin{array}{c}\text { IC31- } \\
\text { Technology } \\
\text { awareness } \\
\end{array}$ & IC31.a & $\begin{array}{c}\text { Is there a specific team } \\
\text { for technology } \\
\text { awareness? }\end{array}$ \\
\hline & $\begin{array}{l}\text { IC32- Customer- } \\
\text { driven innovation }\end{array}$ & IC32.a & $\begin{array}{l}\text { Does the IT department } \\
\text { have tools to collect } \\
\text { customer feedback on } \\
\text { the company's products } \\
\text { and services? }\end{array}$ \\
\hline & $\begin{array}{l}\text { IC33- Innovation } \\
\text { with business } \\
\text { value addition }\end{array}$ & IC33.a & $\begin{array}{l}\text { What is the } \\
\text { contribution's level of } \\
\text { IT department to } \\
\text { improve the existing } \\
\text { products? }\end{array}$ \\
\hline
\end{tabular}

\section{AgILITy LEVELS}

The concept of levels in the CMMI model [8] inspired us to introduce IT agility levels in our ITAAM approach.

The goal is not to build a certification model, but to help IT organizations identifying their true agility needs and to be able to maintain and improve them on an ongoing basis.

The challenge now is to determine the nature of these levels and how to define them. Levels of agility represent, in a way, the roadmap that an information systems needs to follow gradually to pave a path to agility. Again, CMMI is helping. A staged representation of levels is a model that suits our need, and best describes a gradual deployment of agility in stages, where each level is a prerequisite of the higher level.

Generally an organization starts at level 1 , so it seems 
normal to say that this level is initial, basic or elementary. This level is characterized by an anarchic management of IT, where changes are not mastered and considered as a threat and not an opportunity to be more competitive in the market.

Given the definition of agility we have adopted in this work, we can gradually define the different levels in order to achieve the goal of an agile organization to maintain its competitiveness in a constantly changing environment. Table 2 shows the agility levels identified with their corresponding characteristics.

Table 2. Definition of ITAAM agility levels

\begin{tabular}{|c|c|c|}
\hline Agility level & Description & Characteristics \\
\hline Elementary & $\begin{array}{l}\text { The IT is a provider } \\
\text { of IT resources and } \\
\text { skills with best effort } \\
\text { management }\end{array}$ & $\begin{array}{l}\text {-Competence center } \\
\text {-Cost center } \\
\text {-Best effort mode } \\
\text {-Lack of a Culture of } \\
\text { Change }\end{array}$ \\
\hline Intermediate & $\begin{array}{l}\text { IT agility partially } \\
\text { introduced }\end{array}$ & $\begin{array}{l}\text {-Classic IT management } \\
\text {-Basic concepts on IT } \\
\text { agility } \\
\text {-Introduction of agility } \\
\text { criteria for some } \\
\text { processes or IT areas } \\
\text {-Start of partnership with } \\
\text { users }\end{array}$ \\
\hline Developed & $\begin{array}{l}\text { Popular agile culture } \\
\text { and controlled } \\
\text { changes }\end{array}$ & $\begin{array}{l}\text {-Popular agile culture in } \\
\text { the whole organization } \\
\text {-Agility criteria applied in } \\
\text { most processes and } \\
\text { internal structures, } \\
\text {-Agility of Human } \\
\text { Resources and } \\
\text { Technology } \\
\text {-A strong partnership with } \\
\text { users }\end{array}$ \\
\hline Advanced & $\begin{array}{l}\text { Innovation, learning } \\
\text { and continuous } \\
\text { improvement to keep } \\
\text { the company more } \\
\text { competitive in a } \\
\text { changing } \\
\text { environment }\end{array}$ & $\begin{array}{l}\text { - Innovation, learning and } \\
\text { continuous improvement } \\
\text {-Value delivery and faster } \\
\text { Time-to-Market }\end{array}$ \\
\hline
\end{tabular}

\section{Global Assessment Methodology}

ITAAM is a balanced and flexible approach, in terms of both its multi-perspective vision of agility and the ability of its evaluation methodology that can be adapted to the context of any organization.

An important question before deciding how an organization can measure its IT agility, is first of all how an information systems could become agile, the answer is obvious, an IS is becoming increasingly agile when it deploys more key success factors and criteria according to ITAAM. An IS that is characterized with more key success factors and agile criteria is probably more agile than an IS that deploys less or nothing. This fundamental concept helps us to answer the crucial question, how to measure the agility of an IS, it is through the number of key success factors and criteria that characterizes it. Thus, the Global Agility Index (GAI) is designed to measure the agility of information systems. The next question is which unit can be used to measure this index, a simpler solution is to count the number of key success factors (KSF) and criteria adopted and then sum up to have the agility score. This approach is very simplistic and imprecise, because there are other issues that must certainly be considered, essentially the impact of each element of evaluation on the agility of the organization.

This last point is extremely important because the need for agility is not necessarily the same from one organization to another, the ITAAM evaluation system uses a criteria and weighting mechanism to better adjust the company's needs. On the other hand, each criterion is evaluated through questions measured by metrics that may be of different natures (quantitative, qualitative).

To standardize the interpretation of the results and the calculation, we chose to standardize the evaluation metrics on a Likert-5 scale. Indeed, each metric is measured on a five-point scale ranging from (1) very low to (5) very high [Very low $=1$; Low $=2 ;$ Medium $=3$; High $=4 ;$ Very high $=5$ ]. In particular, a metric could have the value "NA" in case the question is not applicable to the organization context. Therefore, the criterion is totally excluded from the calculation of the key success factors agility if all its associated questions are not applicable. This principle is often used for the adjustment of ITAAM during a new deployment of this approach.

\section{A. Methodology description}

In their study of organizational agility, Wensley and van Stiju [12] mention the importance of maintaining agility at the organizational level. This aspect is particularly important for IT as they continually need to upgrade their skills to ensure continued agility. The Deming Wheel, also known as the PDCA (Plan, Do, Check and Act) cycle, is a process that consists of a fourphase. Logical sequence is repeated for continuous improvement as shown in the figure below.

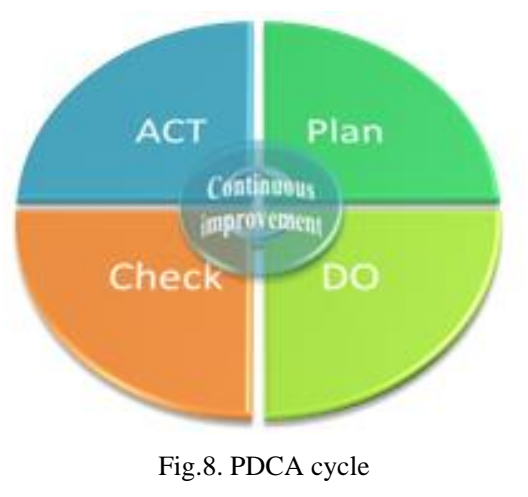

The PDCA cycle [5] inspired us in developing our Agility Assessment methodology for information systems, which is a cyclical approach that consists of several steps as described in Fig.9. Each assessment cycle is called the ITAAM Cycle. 


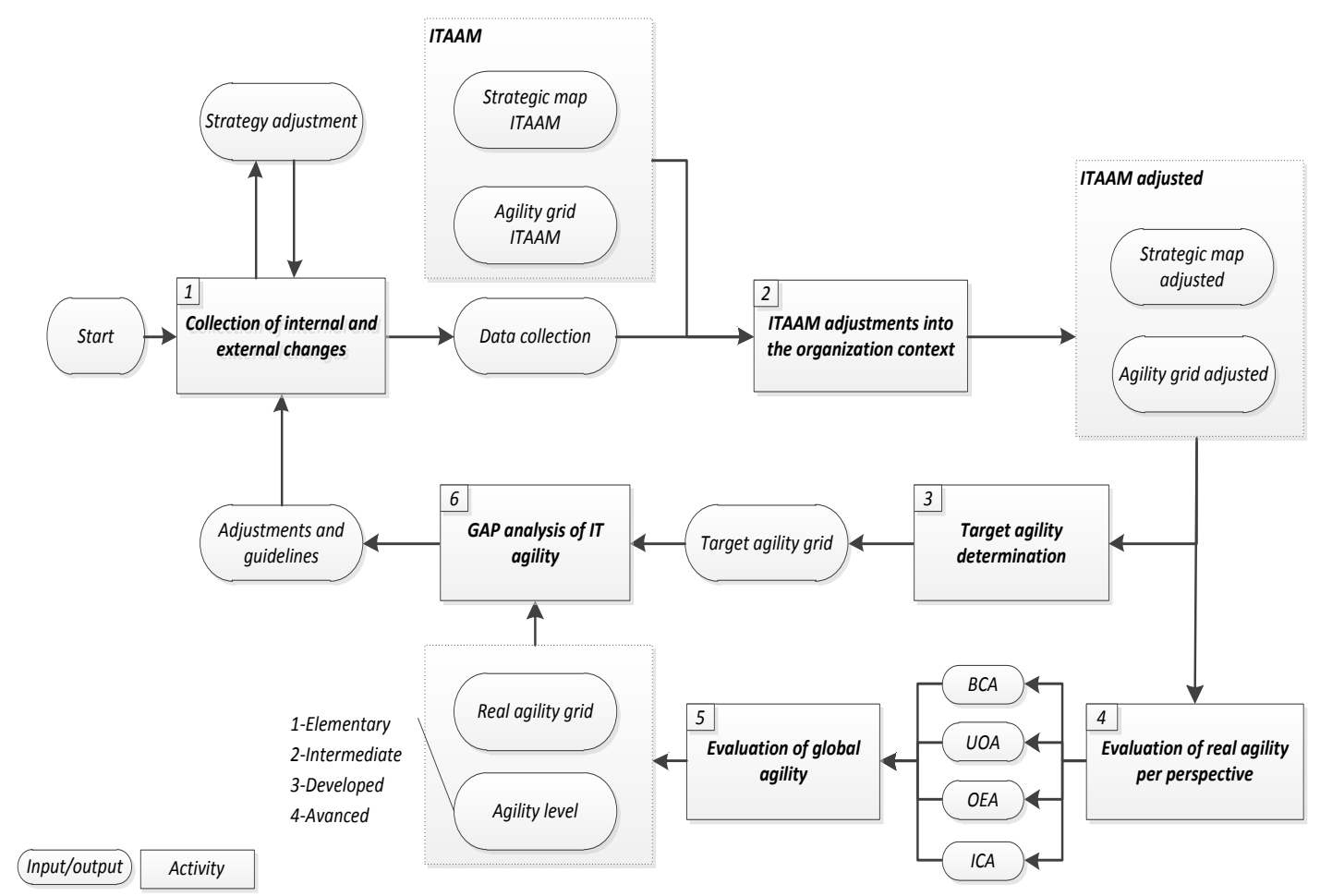

Fig.9. ITAAM methodology for IT agility evaluation

The performance of IT agility depends on adapting the concept of agility to the context and culture of the organization. Because each organization is different, IT agility is measured depending on the company's history, culture and context. Indeed, the ITAAM model is designed to be flexible.

In a first step, the IT department and the business must share a common vision on the agility of their information system. Thus, the organization's strategy is reviewed or defined in order to determine the effective need of IT agility. For this aim, ITAAM methodology begins by collecting the needs for changes that may be made internally or externally to the IS. In this way, ITAAM allows the IT department to be adapted continuously at the context and the new orientations of the organization. Changes can come from different sources; either at the strategic level such as a new regulation impacting an application heritage, or from the requirements to reach a specific level of agility, or at the end of an ITAAM Cycle as a kind of guidelines, or these changes may also be technical, organizational or functional changes detected through the Innovation and Competitiveness perspective of ITAAM through the monitoring mission.

In the second step, the agility grid is adapted, the strategic map is adjusted and the weights of the criteria and the key success factors are determined. In order to detect possible ITAAM adjustments, it is necessary to conduct a Zero Evaluation of the actual IT agility within the organization. This first evaluation has a double purpose. On the one hand, it ensures the clarity and completeness of the questionnaires, and on the other hand, it determines the applicability of the criteria and questions to the context of the organization. Before launching the questionnaires, interviews should be considered to better explain the content of the questions and to ensure their understandings. These interviews could lead to changes to existing questions or even the addition of new questions (Rule 2).

The third step generates the target agility grid that defines the desired level of IT agility. This involves defining target metrics (from 1 to 5) for each of the criteria in the adjusted ITAAM grid. Each metric represents the ideal score that a criterion should have in the agile information system. In this regard, collaboration with experts may be necessary to determine the value (from [1 to 5]) to which a criterion should be noted.

In order to measure IT agility, we launch the questionnaires to assess the agility of each of the perspectives. The metrics obtained allow to evaluate the criteria, then to go back to evaluate the key success factor, then the agility of each perspective [ABC: Agility of the Business Contribution perspective, AUO: Agility of User Orientation perspective, AOE: Agility of Operational Excellence perspective; AIC: Agility of Innovation and Competitiveness perspective]*. In the Global Agility Assessment step, the results are combined, the actual agility grid is obtained, the global agility index (GAI) is calculated, and hence the IT agility level is determined.

At the end of an ITAAM cycle, the IT agility deviation (GAP) is identified by comparing the actual value of the agility with the target value. The GAP represents the inadequacy between the need for the IS in terms of agility and the performance of the agility of the IS. It can be either a lack of performance or a surplus. In any case, the analysis of non-conformities must define guidelines of adjustments, appropriate with the strategy of the organization, in order to achieve the desired performance of the IT agility. 


\section{B. Evaluation rules}

Rule 1: Each criterion and key success factor has a weight depending on the higher level of the BSC. This weight is assigned based on the importance and priority of the criterion and key success factor for the organization. Indeed, a criterion is weighted according to its rate of contribution to the performance of the key success factor. Similarly, a key success factor is weighted according to its importance and priority to achieve the desired level of agility of the perspective. The weights have numerical values in percentage format. In addition, for a key success factor, the sum of the criteria weights must be $100 \%$. Similarly, the sum of the key success factors weights is $100 \%$ within the same perspective. For example, the Speed to response improvement of User Orientation perspective is weighted to $30 \%$.

Table 3. Example of weights of key success factors

\begin{tabular}{|c|c|}
\hline Key success factor(KSF) & Weight \\
\hline Speed to response improvement & 30 \\
\hline Quality improvement & 30 \\
\hline Partnership with users & 25 \\
\hline IT cost effectiveness & 15 \\
\hline
\end{tabular}

As shown in the Table 4, the Collaboration criterion of Partnership with users is weighted to $40 \%$.

Table 4. Example of weighting criteria

\begin{tabular}{|c|c|}
\hline Evaluation criteria & Weight \\
\hline Collaboration & 40 \\
\hline Communication efficiency & 40 \\
\hline Trust based relationships & 40 \\
\hline
\end{tabular}

Rule 2: After an assessment, if a question is judged not applicable by more than $70 \%$ of the population, then it is considered not applicable in the consolidated result. However, the criterion is considered not applicable if all its associated questions are judged not applicable.

Rule 3: A key success factor must have at least one applicable evaluation criterion.

Rule 4: The final score of a question is the average of answers to this question by the survey population. If the question is applicable (see Rule 2), the answers with the value "NA" are not included in the calculation of the mean score of the question, however, theses answers will be analyzed separately.

Rule 5: The Global Agility Index (GAI) is the result of evaluating the agility of each of four perspectives. It is calculated as follows:

$$
G A I=\frac{(B C A+U O A+I C A)}{4}
$$

- BCA: Agility index of business contribution perspective

- UOA: Agility index of user orientation perspective

- OEA: Agility index of operational excellence perspective
- ICA: Agility index of innovation and competitiveness perspective

The agility of the perspective $\lambda(\mathrm{AP} \lambda)$ is calculated according to the following formula:

$$
A P_{\lambda}=\frac{\sum_{i=1}^{i=N F}\left(P F_{i} \times A F_{i}\right)}{\sum_{i=1}^{i=N F} P F_{i}}
$$

- $\mathrm{AFi}$ is the agility of the $\mathrm{i}^{\text {th }}$ key success factor $\left(\mathrm{KSF}_{\mathrm{i}}\right)$

- $\mathrm{NF}$ is the number of $\mathrm{KSF}$ regarding $\mathrm{P} \lambda$ perspective

- $\mathrm{PF}_{\mathrm{i}}$ is the weight of $\mathrm{KSF}_{\mathrm{i}}$

$$
A P_{i j}=\frac{\sum_{j=1}^{j=N C}\left(P C_{i j} \times A C_{i j}\right)}{\sum_{j=1}^{j=N C} P C_{i j}}
$$

With:

- $\quad \mathrm{AC}_{\mathrm{ij}}$ : The agility of the $\mathrm{j}^{\text {th }}$ evaluation criterion of $\mathrm{KSF}_{\mathrm{i}}$. For each question, the user estimates a score of 1 to 5 . The score of a criterion is the weighted average of the scores of each of its associated questions which is the average score of the questions.

- $\quad \mathrm{NC}$ is the criteria number of $\mathrm{KSF}_{\mathrm{i}}$

- $\mathrm{PC}_{\mathrm{ij}}$ is the criterion weight of $\mathrm{KSF}_{\mathrm{i}}$

We deduce, from (2) and (3), the detailed formula for calculating the agility of an ITAAM perspective:

$$
A P_{\lambda}=\frac{\sum_{i=1}^{i=N F} \sum_{j=1}^{j=N C}\left(P F_{i} \times P C_{i j} \times A C_{i j}\right)}{\sum_{i=1}^{i=N F} \sum_{j=1}^{j=N C}\left(P F_{i} \times P C_{i j}\right)}
$$

Thus, the global agility index GAI is calculated regarding the following formula:

$$
G A I=\frac{\sum_{\lambda=1}^{\lambda=4} A P_{\lambda}}{4}
$$

Table 5. Rules for determining ITAAM agility level

\begin{tabular}{|c|c|c|}
\hline Global Agility Index & IT Agility level & Level identification \\
\hline $1<\mathrm{GAI}<=2$ & Elementary & Level 1 \\
\hline $2<\mathrm{GAI}<=3$ & Intermediate & Level 2 \\
\hline $3<\mathrm{GAI}<=4$ & Developed & Level 3 \\
\hline $4<\mathrm{GAI}<=5$ & Advanced & Level 4 \\
\hline
\end{tabular}

Rule 6: An IS will have an agility level determined by perspective (these levels may be different depending on the perspective). A curve can be plotted to see the variations of the different levels assigned to the IS, compared to the ITAAM perspectives. 


\section{CONCLUSION AND FUTURE WORK}

In this paper, we presented the ITAAM framework as a new integrated approach to design measure and improve IT agility. Through such approach, executive directors as well as top management can monitor, in a natural and logical way, the agility performance of their information system, and know how to improve it. The objective of this paper is also to describe in detail the structure of the ITAAM framework. Indeed, two main components are presented; first, the conceptual model that define and conceptualize IT agility through four balanced perspectives based on key success factors and evaluation criteria. Second, an assessment system that contains basically a global assessment methodology which continuously evaluates IT agility level based on four questionnaires of the agility grid called ITAAM grid. So, at the end of every evaluation or ITAAM Cycle the level of agility is determined among four agility levels as defined in this paper.

In perspective, we intend to extend the ITAAM framework at the enterprise level to assess its agility. Moreover, in order to put into practice this approach, more case studies should be conducted in companies of various sizes and sectors such as industry, banking, public administration and others. Indeed, we believe that the framework can be adapted and generalized by sector of activities or by group of sectors that have common concerns and almost the same issues (level of competition, competitiveness, changes, etc.).

\section{REFERENCES}

[1] Aubert, B., Cohendet, P., Da Silva, L., Grandadam, D., Guimaron, J., \& Montreuil, B. (Octobre 2010). L'innovation et les technologies de l'information et des communications, publié simultanément par le CEFRIO et le Centre sur la productivité et la prospérité de HEC Montréal.

[2] Dyba, T., \& Dingsoyr, T. (2015, May). Agile Project Management: From Self-Managing Teams to Large-Scale Development. In Software Engineering (ICSE), 2015 IEEE/ACM 37th IEEE International Conference on (Vol. 2, pp. 945-946). IEEE.

[3] Hummel, M., \& Epp, A. (2015, January). Success Factors of Agile Information Systems Development: A Qualitative Study. In System Sciences (HICSS), 2015 48th Hawaii International Conference on (pp. 5045-5054). IEEE.

[4] Knabke, T., \& Olbrich, S. (2013, January). Understanding Information System Agility--The Example of Business Intelligence. In System Sciences (HICSS), 2013 46th Hawaii International Conference on (pp. 3817-3826). IEEE.

[5] Moen, R., \& Norman, C. (2006). Evolution of the PDCA cycle.

[6] Moran, A. (2015). Agile Project Management. In Managing Agile (pp. 71-101). Springer International Publishing.

[7] Rdiouat, Y., Bahsani, S., Lakhdissi, M., \& Semma, A. (2015). Measuring and Improving Information Systems Agility Through the Balanced Scorecard Approach. International Journal of Computer Science
Issues (IJCSI), 12(5), 58.

[8] Rdiouat, Y., Nakabi, N., Kahtani, K., \& Semma, A. (2012). Towards a new approach of continuous process improvement based on CMMI and PMBOK. International Journal of Computer Science Issues (IJCSI).

[9] Salmela, H., Tapanainen, T., Baiyere, A., Hallanoro, M., \& Galliers, R. (2015). IS Agility Research: An Assessment and Future Directions.

[10] Teoh, S. Y., \& Cai, S. (2015). The Process of Strategic, Agile, Innovation Development: A Healthcare Systems Implementation Case Study. Journal of Global Information Management (JGIM), 23(3), 1-22.

[11] Version, T. O. G. A. F. (2009). 9, the open group architecture framework (togaf).The Open Group, 1 ..

[12] Wensley, A., \& van Stijn, E. (2006). Enterprise information systems and the preservation of agility. In Agile Information Systems. Butterworth-Heinemann.

[13] AlMutairi, A. M., \& Qureshi, M. R. J. (2015). The Proposal of Scaling the Roles in Scrum of Scrums for Distributed Large Projects. International Journal of Information Technology and Computer Science (IJITCS), 7(8), 68.

[14] Sakthivel Aravindraj S. Vinodh , (2014),"Forty criteria based agility assessment using scoring approach in an Indian relays manufacturing organization", Journal of Engineering, Design and Technology, Vol. 12 Iss 4 pp. $507-518$.

[15] Overby, E., Bharadwaj, A. and Sambamurthy, V. (2006). Enterprise agility and the enabling role of information technology. European Journal of Information Systems, 15 (2), 120-131.

[16] Liu H., Ke W., Wei K.K., and Hua Z., 2013 (2013) “The impact of IT capabilities on firm performance: The mediating roles of absorptive capacity and supply chain agility." Decision Support Systems, 54(3) 1452-1462

[17] Dyba, T., \& Dingsoyr, T. (2015, May). Agile Project Management: From Self-Managing Teams to Large-Scale Development. In Software Engineering (ICSE), 2015 IEEE/ACM 37th IEEE International Conference on (Vol. 2, pp. 945-946). IEEE.

[18] Sharifi, H., \& Zhang, Z. (1998, July). Enabling practices assisting achievement of agile manufacturing. In Proceeding of the 6th IASTED International Conference (pp. 62-65).

[19] Sharifi et al., 2001]Sharifi, H., Colquhoun, G., Barclay, I., \& Dann, Z. (2001). Agile manufacturing: a management and operational framework. Proceedings of the Institution of Mechanical Engineers, Part B: Journal of Engineering Manufacture, 215(6), 857-869.

[20] Achi, A., \& Salinesi, C. (2015, May). Proposition d'un modèle d'innovation par l'usage des SI. In INFORSID.

\section{Authors' Profiles}

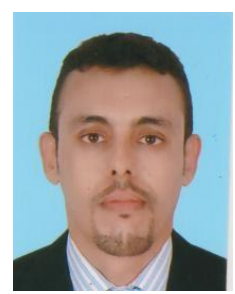

Yassine Rdiouat is a PHD. Student at Hassan 1st University, Settat city, Morocco. He took his engineer degree in Computer Sciences from ENSIAS high school in 2004 at Morocco.

$\mathrm{He}$ is working since 2004 as a private consultant for the account of national and international customers, a part time teacher for several high schools and a professional trainer en management and quality assurance. 


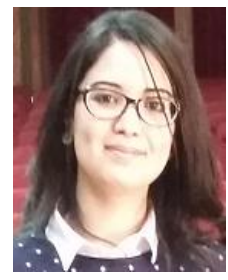

Wafaa Dachry was born in Casablanca in 1985. She received his $\mathrm{PhD}$. in information system engineering from the Hassan II University, Casablanca, Morocco, 2013. She is an Assistant Professor at Faculty of Science and Techniques, Hassan 1st University, Settat city, Morocco. Her main research focuses on IT Governance, reverse logistics and traffic control system based on multi-agent system.

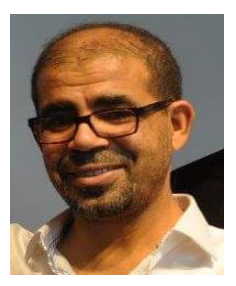

Alami Semma is a Professor at Faculty of Science and Techniques, Hassan 1st University, Settat city, Morocco. He received his $\mathrm{PhD}$ in 2004. His research focuses on information systems, supply chain and industrial management. He is the author of several articles and Member/organizer of several international conferences. He is the director of the Centre of Excellence in Industrial Engineering, Hassan 1st University, Settat city, Morocco.

How to cite this paper: Yassine Rdiouat, Wafaa Dachry, Alami Semma, "ITAAM Framework: An Adaptive Approach to Design, Measure and Improve IT Agility", International Journal of Information Technology and Computer Science(IJITCS), Vol.9, No.10, pp.37-46, 2017. DOI: 10.5815/ijitcs.2017.10.04 